\title{
Sudden Asphyxia Due to a Laryngeal Lipoma Following Esophageal Endosonography
}

Esophageal endosonography is now widely used, especially for staging esophageal carcinoma. It is currently recognised a routine procedure with few complications. We report the case of a 74-year-old patient who experienced a novel complication of esophageal endosonography. During endoscopic monitoring of an esophageal adenocarcinoma $(32-36 \mathrm{~cm}$ from the incisors) treated by chemoradiotherapy, an odd bulge was discovered in the upper part of the esophagus $(20-25 \mathrm{~cm}$ from incisors). Biopsy findings remained negative. Endosonography showed an hyperechogenic and homogeneous lesion, on the left part of the esophagus, $17-21 \mathrm{~cm}$ from the incisors, i.e., in a different location from that previously measured (Figure 1). The diameter and thickness of the lesion were, respectively $26 \mathrm{~mm}$ and $11 \mathrm{~mm}$. The submucosa and muscularis mucosa were intact and no evidence of recurrence of carcinoma in the lower part of the esophagus was noted.

Withdrawal of the endosonography probe was followed by a sudden asphyxia, and emergency tracheotomy was carried out. Laryngeal examination showed a pedunculated lipoma implanted in the larynx. A $40 \times 25 \times 20 \mathrm{~mm}$ lesion, which had developed from the arytenoid cartilage with a long and pedunculated implantation, was

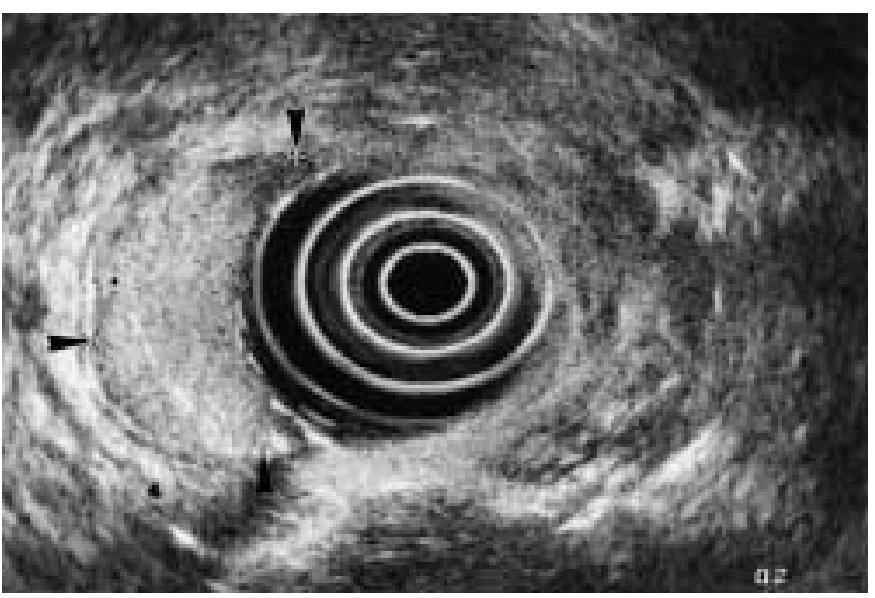

removed. The endosonography probe had moved the lipoma into the glottis, leading to acute asphyxia. To our knowledge, it is the first time that such a complication has been reported with an endosonography probe.

Fewer than 100 cases of laryngeal lipomas have been reported in the literature. These are benign tumors, whose symptoms include dysphagia, dyspnea, dysphonia or hoarseness, and excessive salivation [1,2]. Clinical manifestations depend on the lipoma's position. Moreover, lipomas are often pedunculated and therefore able to migrate into different sites, which often explains a variety of symptoms [3-5]. Thus the removal of symptomatic laryngeal lipomas must be routinely performed, by endoscopy or external surgery as in our patient.

\section{Acknowledgements}

The authors thank Mr. Richard Medeiros for his advice in editing the manuscript.

\section{S. Lecleire, F. Di Fiore, I. Roque, M. Antonietti, S. Hervé, G. Savoye, P. Michel, E. Lerebours \\ Digestive Tract Research Group, ADEN EA 3234, Rouen, France}

Figure 1 Endosonographic image showing the lipoma in the esophagus $(40 \times 25 \times 20 \mathrm{~mm})$.

\section{References}

${ }^{1}$ Yoskovitch A, Cambronero E, Said S et al. Giant lipoma of the larynx: a case report and literature review. Ear, Nose Throat J 1999; 78: 122 - 128

${ }^{2}$ Wenig BM. Lipomas of the larynx and hypopharynx: a review of the literature with the addition of three new cases. J Laryngol Otol 1995; 109: 353-357

${ }^{3}$ Akiyama S, Kataoka M, Horisawa M et al. Lipoma of the oesophagus-report of a case and review of the literature. Jpn J Surg 1990; 20: $458-462$

${ }^{4}$ Peiser J, Ovnat A, Herz A et al. Lipoma of the oesophagus. Isr J Med Sci 1984; 20: $1068-1070$

${ }^{5}$ Jungehulsing M, Fischbach R, Pototschnig $C$ et al. Rare benign tumours: laryngeal and hypopharyngeal lipomata. Ann Otol Rhinol Laryngol 2000; 109: 301 305

\section{Corresponding Author}

\section{S. Lecleire, M.D.}

Department of Hepatogastroenterology and Nutrition

Rouen University Hospital

Charles Nicolle

1 , rue de Germont

76031 Rouen Cedex

France

Fax: $\quad+33-2-35151623$

E-mail: stephanelecleire@ hotmail.com 